\title{
A Finite Horizon Inventory Model: An Operational Framework*
}

\begin{abstract}
We present a simulation based decision support system to decide the inventory ordering policy in the context of a single commodity, multi pack, and finite horizon situation. The multiple objectives include (a) Minimizing the end of the season inventory, (b) Maximizing the operating profit, (c) Minimizing the peak working capital requirements during the season. Stochastic demand and positive lead time add to the complexity of the problem context. In addition multiple partners in the supply chain with distinct and conflicting set of objectives necessitate the need for a formal approach.
\end{abstract}

The motivation for this model is based on a real life situation. The model addresses the decision choices faced by the distributor in a specific logistics chain. In this chain, a typical distributor has to balance between the stochastic nature of the demand and the attractive nature of financial incentives (order quantity based) proposed by the manufacturer.

The problem can be formulated as a multi-period dynamic programming problem with stochastic demand with an objective to optimize the expected operating profit, subject to specific constraints on working capital requirement, service level, order fill rate and end of the season inventory. Such a formulation is hard to solve and does not lend itself to analyze several ordering policies.

Based on simulation experiments, we propose an ordering policy which optimizes the overall objectives of supply chain partners and hence demonstrated the possibility of jointly managing the uncertain demand by supply chain partners.

The model is simple and easy to use. It is implemented by using spreadsheet. It provides adequate flexibility to conduct what-if analysis. The model has a potential to be useful in a wide range of situations.

\footnotetext{
* N. Ravichandran, Professor of Operations Management and Strategy, Indian Institute of Management, Ahmedabad 380 015, India.
} 


\section{Introduction}

In this paper we discuss and present an analysis of an Inventory Model motivated by a real life example. The conceptual modeling of the problem is based on the physical distribution structure, inventory flow management practices and the existing operating performance. We deal with a context where demand is seasonal in a finite time horizon. The inventory management has significant impact on various partners in the supply chain viz. the organization, the marketing regional offices, distributors and dealers. The uncertainty arising out of consumption variability and demand seasonality is presently resolved by using the bargaining position of the supply chain partners, leading to suboptimal performance of the supply chain.

In this article, we present a methodology by which the fundamental problem of inventory management can be resolved to the satisfaction of all the partners in the supply chain. Analytical solution to the general problem formulation is difficult. Hence, we developed a simulation model to understand the implications of the inventory policy options (how much and when to order). As a by product to enhance the utility of this approach we have designed a spreadsheet based decision support system.

In addition to the excitement of solving an inventory problem motivated by a real life context, the present paper documents an alternative methodology to handle uncertainty to the mutual satisfaction of the partners in the supply chain. This we believe is the unique contribution of this article.

\section{Problem Context}

We discuss an inventory problem in the context of an organization which produces pesticides for plant protection in India. The organization being a multinational is present in several countries and India is one of the key markets for this organization. The company produced and marketed several products to suit the requirements of multiple crops in the Indian sub-continent. Accordingly, the diverse product portfolio of the 
company was very specific to market segments. In this article, we deal with two specific products of the organization in the broad category of pesticides used for protecting cotton crop. For identification purpose the products will be named as Product 1 and 2. These products are known to be technologically superior. They are premium priced and sold on brand. The Indian pesticides market is crowded with several (both national and MNC) players in the market. Often, the product is substitutable by competitors' products. Marginal farmers (with small land holding) constituted the consumer segment of product 1 and 2. In order to achieve its aggressive sales target, the organization routinely used several promotional efforts like discounted sales, dumping of stocks, turnover based sales incentives, and target based financial and non-financial incentives. For additional details on holding pattern, economics of cotton cultivation see Table 1 and 2.

The company has its manufacturing facility in Bombay. For marketing purpose, the Indian sub continent was divided into several regions each of which was managed by a senior company executive. The regional offices were treated as profit centers. The key performance parameters for a Regional Manager included turnover, cost of sales, gross margin, and inventory turns. By a combination of appropriate performance measures, the organization forced the regional managers to meet the company targets.

The Regional Managers in turn controlled and managed several distributors. Distributors are typically entrepreneurs located in large towns. The sales margin motivated them to be in this business. For details related to sales margins of Product 1 and 2 please refer to Table 3. In view of the restrictive credit policy up to three weeks in the peak season by the company and the investment involved, the distributors were conservative in their inventory planning. They were sandwiched between the uncertainty in demand arising out of sales fluctuations and the strict company credit policy and attractive promotional (sales) offers. The distributors in turn supplied material to the retailers. The retailers were large in number, spread geographically wider and were closer to the farmers representing the actual point of sale. 
The company operated a business philosophy of (a) no credit (but for peak season), (b) aggressive sales target, (c) premium product price position and (d) frequent stock transfer among regions (held for more than a specified duration of time). The production for Product 1 was scheduled once in a year in a single batch run.

Pesticides being technological input to enhance the crop yield were recommended to be administered by farmers according to a spraying schedule (Table 4). More often, the farmers did not adhere to the recommended schedule for a variety of reasons. In addition, pest occurrence was also influenced by climatic conditions. The prevailing marketing prices of cotton in a particular season influenced the crop area in the following season. The cotton crop life is four months. Often there was a significant spread (time) on the sowing pattern of the farmers in a given region (Table 5). The combination of these factors led to an unpredictable seasonable demand.

Being a MNC company the organization was focused on turnover and gross margins. Significant emphasis was laid in mitigating the risk associated with the single production batch of pesticides. The regional managers were monitored strictly on the performance of inventory turns. The company managed the demand fluctuations by repeated stock transfers across the regions. The company used the sales representatives to aggressively push the stock from the regions to the distributors. Stocks sold to the distributors are never taken back. Unsold stocks at the regional level will distort the financial performance of the region and may have an adverse impact on the career progress and financial incentives of the regional managers. However, the financial consequences are not real.

Inappropriate inventory management at the distributor level will lead to extended credit limits, increase in working capital, higher end of the season inventory, reduction in the overall gross margin and profitability. The financial consequences are real at the distributor level. Usually, the distributors extended credit to retailers on need basis. This business practice further eroded the gross margin to the distributor. 
In short, the inventory management problem at the distributor level can be characterized as multi period, finite horizon, and stochastic demand situation. The company has been following a policy of motivating distributors by appropriate incentive schemes to order more stock from the regional offices. This essentially transformed the risk of unsold inventory from the company to the distributors. As a consequence, there was a tremendous conflict of interest between the distributors and the regional offices in managing the inventory in the context of regional demand (for additional details see Table 6).

\section{The important features of the problem context $[5,3]$ are summarized below.}

- The planning horizon is finite.

- The demand is stochastic, subject to seasonal fluctuations

- The financial risk associated with unsold inventory is real among the distributors and retailers. This risk is conceptual at the branches. For the organization, the residual inventory would be a fraction of overall profitability and therefore is not a source of major risk.

- The financial performance arising out of poor inventory management or otherwise would have significant impact on the distributors and retailers

- Over a period, instead of planning a response for the demand uncertainty, the organization has developed a negotiation methodology and a bargaining procedure by which the sales representatives of the organization persuade the distributors to order more stock.

- The sources of uncertainty include lack of adherence to spraying schedule by farmers, prolonged and unpredictable sowing pattern, variability in the climatic conditions and unpredictable nature of pest occurrence

- Lead time between the factory and the regional offices was significant (10 days).

- The substitutable nature of the product, crowded market place, and aggressive competition added additional dimensions to demand variability. 


\section{General Formulation}

There are several objectives that are important for different partners in the supply chain of a situation described above. As far as the organization is concerned, the production quantity is frozen, the demand is unpredictable, and the product can be used only in the context of cotton crop. It attempts to maximize the sales and profit realization based on minimum credit, premium pricing, and aggressive performance measures for the regional managers and dynamic stock transfers among regions. In addition, the organization has financial strength to carry over the inventory to the next season should there be unsold stock.

The regional managers' operational targets were well defined. Key performance measures in terms of revenue collection, inventory turns were agreed upon. They managed to the best of their ability with a motivation to optimize their gross margin. Any deviation in the performance measures did not affect them financially. Their incentives can change.

At the distributor level, the financial consequences of mismanaged inventory were real and significant. The problem at the distributor level can be formulated as a multi period newsboy problem. In each period, based on the current inventory the distributor has to decide how much quantity to order. The objectives included (a) minimizing the end of the season inventory at the distributor, (b) minimize the peak cash flow requirements of the distributor, (c) maximizing the order fill rate and (d) improving the overall financial performance of the operations: revenue - cost of managing operations. Cost of managing operations included inventory cost, ordering cost, back order cost (lost sales cost) and end of the season inventory cost. This problem can be formulated as a multistage stochastic dynamic programming problem $[1,2]$ with an objective to maximize the expected profit from operations in a given season. In this formulation the other objectives like order fill rate, working capital requirement end of the season inventory etc can be expressed as a constraint. However, analytical solution to this problem is complex and is not reported in 
the literature. Therefore, we have chosen to examine policy options based on a simulation model. In the next section we describe the features of this model its relevance and potential.

\section{Simulation Model}

For the purpose this simulation model we concentrate on Product 1 . The same analysis can be carried out to the other product since there is no overlap on product usage and economies of scale in transportation. In order to simplify the simulation model, without compromising the core issue, we have decided to concentrate on a single pack size $(100 \mathrm{ml})$. The variability arising out of multiple pack sizes can be handled by the proposed model. The following are the key features of the simulation model.

- Demand estimation: Based on the inputs on sowing pattern, acreages under cultivation, suggested usage pattern (using bill of material concepts), an aggregate weekly demand estimate was derived. This was apportioned to appropriately $6 \%$ to reflect the market share of the organization (Fig. 1).

- Demand representation: Demand was represented in the simulation model by using two approaches. (a) Demand was assumed to follow a known distribution with expected value equal to the weekly demand derived above and a standard deviation which is one tenths of the average. (b) In order to inject reality to the system, it was assumed that the projected weekly demand was spread over a period of five weeks. This would mean the demand in the $i^{\text {th }}$ week would be spread during (i-2) to ( $\left.i+2\right)$ weeks, according to a pre-determined proportion.

- Demand distribution: Three different demand distributions Viz. Normal, Uniform and a three point estimate based distribution were considered to represent all possible variations.

- Other parameters: Wherever appropriate and applicable, a one week procurement lead time was assumed. Cycle service level was aimed at 95\%. Ordering cost, inventory carrying cost, back order cost, end of season inventory cost were explicitly considered. The model provisioned for both lost sales and back order situations, of unmet demand. 
- Policy options: Three different policy options were considered. (1) Periodic Review policy with a review period of one week. (2) An ROP, EOQ policy, (3) A Newsboy model based approximation.

- Performance measures: The performance measures considered included end of the season inventory, maximum working capital requirements, number of stock out occurrences, stock out quantity, order fill rate and overall profitability in operating an inventory policy for a season.

- Simulation design: The model was simulated for 200 runs. Each run representing the entire planning horizon of 21 weeks. The performance measures were accumulated and appropriate averages were considered (Table 7). In order to compare the alternative policies, common random numbers were used in the simulation design [3].

\section{Results and Discussion}

The periodic review policy and the ROP, EOQ policy performed very poorly in terms of several performance measures (Fig 2, 3, 4 and 5). Therefore, it was decided not to pursue this option. The policy parameters related to the periodic review system was weekly review and one week procurement lead time with $95 \%$ service level.

The ROP, EOQ model required some additional assumptions. The procurement lead time was taken 3 days. The daily demand was apportioned from weekly demand. The model was decomposed to four distinct cycles corresponding to the ramps in the original demand profile. EOQ was computed using the demand for the four weeks under consideration. ROP was computed based on $95 \%$ service level and safety stock.

The reason for this poor performance of Periodic review and ROP, EOQ policy [6, 7] was very simple. The prescribed usage of pesticides generated four distinct cycles of demand and hence any policy which did not explicitly consider the demand dynamics in a given week resulted in poor performance in terms of end of season inventory and average inventory holding. The most important insight from this experience is an effective (how much to order and when to order) policy has to be dynamic and possibly envelope the projected demand profile (Fig. 1). 
Therefore, a simple newsboy approximation was tried out. In this approximation, based on the service level for a given week, an order was placed by a distributor. Because the ordering cost is negligible, no attempt was made to optimize the number of orders. The ordering quantity was allowed to vary based on market conditions. The system captured all back orders. The order quantity was adjusted for inventory on hand, net of back orders. There was a positive procurement lead time of two days. However, this was integrated in the system by placing the order two days ahead of the next week. In short, we superimposed several single period Newsboy models in conjunction. The performance of this model was found to be superior to other inventory policies and the results are reported in the separate set of graphs (Fig 6,7 and 8).

The performance measures related to cash flow for various policy options are at best conservative. This is a consequence of the implicit assumption in the model that the supplier credit to the distributor is 3 weeks and the distributor credit to the dealer is zero weeks. Consequently the working capital requirements projected for periodic review and continuous review system are optimal. The need for working capital in both the cases is a consequence of accumulated inventory held in the system (this in effect means the policy parameters are non-optimal). In the case of Newsboy approximation, as the inventory held in the system is relatively small, the working capital requirement is zero. Under this policy, the distributor has significant positive cash flow. In order to estimate the working capital requirement under realistic conditions, we simulated the Newsboy approximation policy (for demand represented by Normal distribution) for various dealer credit options. The supplier credit (at the distributor level was kept at 3 weeks). Three policies for dealer credit namely sale on cash, collection at the end of the season and six weeks credit period was considered. The actual results are summarized in Table 8 .

\section{Extensions}

So far we have not used the historical information in updating the demand. The policies proposed earlier considered the demand projected at the beginning of the season. In order to involve the distributor and the sales agent of the company explicitly, we have developed a three point estimate for the demand for any week. This three point estimate 
consisted of (a) the original demand estimate (with two thirds weight age), (b) an estimate proposed by the distributor based on the market environmental factors (with one sixth weight age), and (c) an estimate proposed by the organization sales representative based on issues related to balancing the company objectives and the demand profile (with one sixth weight age). The weighted average and the variance based on this three point estimate are used to represent the demand according to Normal Distribution. The earlier model with a revised demand profile would bring more sensitivity to the model based on historical information from the beginning of the season, contextual relevance, and business sensitivities of the distributor and the sales representative of the organization.

All the variables related to the performance measures, model assumptions are parameterized. Therefore, the simulation model can easily be used to evaluate several ordering policies. The implementation is on spread sheet to enhance the potential usage of the model.

\section{Conclusion}

Motivated by a real life situation, we have developed a comprehensive simulation model which will enable the partners of the supply chain to jointly optimize their respective performance measures in the context of a stochastic (dynamic) demand profile. Even though this model is motivated by a specific situation, it has scope for wider application in several contexts. The simulation model is implemented by using spreadsheet which enhances its utility and possible usage. We have chosen to implement a simple yet versatile model which captures the essential features of the context in terms of demand estimation, inventory management policy, situation arising out of lost sales, service level and order fill rate and the need and ability to update the demand forecast.

The specific insights arising out this study include:

- The need to realign the ordering policy (in terms of when to order and how much to order) dynamically with the demand profile, when the demand is seasonal and stochastic. 
- The power of simple Newsboy model approximation in a seemingly complex simulation in attaining superior performance.

- The effectiveness of a decision support system (and a simulation approach) when multiple objectives in supply chain are relevant.

- An operating procedure to jointly handle demand uncertainty to the mutual benefits of the supply chain partners.

\section{Acknowledgement}

The simulation model presented in this work was developed by Hasmukh Gajjar, Academic Associate, Production \& Quantitative Methods Area of Indian Institute of Management, Ahmedabad. His support is greatly acknowledged.

\section{References}

1. Arrow K. J., Karlin S. and Scarf H. (1958), Studies in the Mathematical Theory of Inventory and Production, Stanford University Press.

2. Hadley G. and Whitin T.M. (1963), Analysis of inventory systems, Prentice Hall, Eaglewood cliffs.

3. Ravichandran N. and Seetharaman S.P. (1991), A Decision Support System for Distribution Planning, Paper presented in the Annual ORSI meeting at Bangalore, December 26-28, 1991.

4. Ross S.M. (1991) A Course on Simulation, Macmillan Publishing Company.

5. Seetharaman S.P. and Ravichandran N. (2003) Hoechst India Limited: Managing Regional Distribution, Indian Institute of Management, Ahmedabad. Prod-251.

6. Silver E.A., Pyke D. F., Peterson R. (1998), Inventory Management and Production Planning and Scheduling, Third edition, Wiley, Newyork.

7. Zipkin P. H. (2000) Foundations of Inventory Management, Mcgraw Hill, Boston. 
Table 1: Economics of Cotton cultivation

\begin{tabular}{|l|c|l|c|}
\hline \multicolumn{1}{|c|}{ Expenses } & Acre & \multicolumn{2}{c|}{ Yield per Acre } \\
\hline Field preparation & 200 & & Quintals \\
\hline Fertilizer & 1,000 & Low & Up to 4 \\
\hline Irrigation & 100 & Medium & $4-8$ \\
\hline Weeding & 200 & Good & $8-12$ \\
\hline Pesticides + Labour & 2,000 & Excellent & $>12$ \\
\hline Harvest & 500 & 1 Quintal =100 Kg. \\
\hline & Rs. 4,000 & Price @ Rs. 800/Quintal \\
\hline
\end{tabular}

Table 2: Holding Pattern

\begin{tabular}{|l|c|c|}
\hline \multicolumn{1}{|c|}{ Information } & Summer & Winter \\
\hline \multicolumn{1}{|c|}{ Total acres } & 20,000 & 40,000 \\
\hline Holding pattern acre & Percentage & Percentage \\
\hline$<1$ & 10 & Nil \\
Up to 2 & 20 & 20 \\
Up to 5 & 50 & 50 \\
Up to 10 & 20 & 20 \\
$>10$ & Nil & 10 \\
\hline
\end{tabular}

Table 3: Trade Margins

\begin{tabular}{|c|c|c|c|}
\hline \multirow{2}{*}{$\begin{array}{c}\text { Pack Size } \\
\text { ml }\end{array}$} & Farmers & Dealers & Distributors \\
\hline & \multicolumn{3}{|c|}{ Price(in Rs.) } \\
\hline 100 & 40 & 36 & 34 \\
\hline 250 & 95 & 86 & 81 \\
\hline 500 & 190 & 170 & 160 \\
\hline 1000 & 340 & 315 & 300 \\
\hline 5000 & 1500 & 1400 & 1325 \\
\hline
\end{tabular}


Table 4: Recommended Spray Schedule

\begin{tabular}{|c|c|c|}
\hline $\begin{array}{c}\text { The Crop } \\
\text { week }\end{array}$ & Chemical & $\begin{array}{c}\text { Qty. } \\
\text { ml }\end{array}$ \\
\hline 3 & Product 1 & 250 \\
\hline 5 & Product 2 & 350 \\
\hline 7 & Product 2 & 500 \\
\hline 9 & Product 1 & 200 \\
\hline 11 & Product 2 & 600 \\
\hline 13 & Product 1 & 200 \\
\hline 15 & Product 2 & 750 \\
\hline 17 & Product 1 & 250 \\
\hline 19 & Product 2 & 1000 \\
\hline 21 & Product 1 & 250 \\
\hline Expenses: Pesticides/Acre $\quad$ Rs. 2,000 \\
Cost of Chemicals & : Rs. 1,200 \\
Spraying & : Rs. 800 \\
\hline
\end{tabular}

Table 5: Sowing Pattern

\begin{tabular}{|l|c|c|}
\hline & Week & $\begin{array}{c}\text { \%of } \\
\text { farmers/Land }\end{array}$ \\
\hline $15^{\text {th }}$ January & 1 & 10 \\
& 2 & 30 \\
& 3 & 40 \\
\hline $15^{\text {th }}$ February & 4 & 20 \\
\hline
\end{tabular}

Table 6: Sources of Conflicts

\begin{tabular}{|c|c|c|c|}
\hline Attributes & Company & Region & Distributor \\
\hline Issues & $\begin{array}{ll}\text { - } & \text { Forecasting } \\
\text { annual demand } \\
\text { - } & \begin{array}{l}\text { Setting business } \\
\text { objectives }\end{array}\end{array}$ & $\begin{array}{ll}\text { - } & \begin{array}{l}\text { Forecasting seasonal } \\
\text { demand }\end{array} \\
\text { - } & \text { Operational and } \\
& \text { Financial Implications }\end{array}$ & $\begin{array}{l}\text { - Smoothen demand } \\
\text { and supply } \\
\text { - Manage day to day } \\
\text { dynamics of demand } \\
\text { and supply }\end{array}$ \\
\hline $\begin{array}{l}\text { Consequences } \\
\text { of Inventory } \\
\text { policy }\end{array}$ & $\begin{array}{ll}\text { - } & \text { In appropriate } \\
& \text { Inventory holding } \\
\text { - } & \text { Too many } \\
& \text { regional transfers }\end{array}$ & $\begin{array}{ll}\text { - } & \text { Poor Forecast } \\
\text { - } & \text { Lost opportunity } \\
\text { - } & \text { Lower sales } \\
\text { - } & \text { Damages to the } \\
\text { market } \\
\text { - } & \text { Lower financial } \\
& \text { objectives }\end{array}$ & $\begin{array}{l}\text { Lower Inventory } \\
\text { - } \quad \text { Lost opportunity } \\
\text { - } \quad \text { Less sales } \\
\text { - } \quad \text { Eroded credibility } \\
\text { High Inventory } \\
\text { - } \quad \text { Poor Financial } \\
\quad \text { performance } \\
\text { - } \quad \text { Ultimate ruin }\end{array}$ \\
\hline Flexibility & Very little & Moderate & Very high \\
\hline
\end{tabular}


Table 7: Comparison of Policy Options (Based on 200 simulation runs)

\begin{tabular}{|c|c|c|c|c|c|c|c|c|c|c|c|c|c|}
\hline \multirow{3}{*}{$\begin{array}{l}\text { Inventory } \\
\text { Policy }\end{array}$} & \multirow{3}{*}{ DR } & \multirow{3}{*}{ Distribution } & \multirow{3}{*}{$B / L$} & \multicolumn{4}{|c|}{ End of the Season } & \multirow{2}{*}{\multicolumn{2}{|c|}{$\begin{array}{l}\text { Max Cumulative } \\
\text { Net Cash Out Flow }\end{array}$}} & \multirow{2}{*}{\multicolumn{2}{|c|}{$\begin{array}{l}\text { Short Supply } \\
\text { (No. of Weeks) }\end{array}$}} & \multirow{2}{*}{\multicolumn{2}{|c|}{ Order Fill Rate }} \\
\hline & & & & \multicolumn{2}{|c|}{$\begin{array}{l}\text { Inventory units } \\
\text { (100 ml pack) }\end{array}$} & \multicolumn{2}{|l|}{ Profit } & & & & & & \\
\hline & & & & Mean & $\begin{array}{l}\text { Std. } \\
\text { Dev. }\end{array}$ & Mean & $\begin{array}{l}\text { Std. } \\
\text { Dev. }\end{array}$ & Mean & $\begin{array}{l}\text { Std. } \\
\text { Dev. }\end{array}$ & Mean & $\begin{array}{l}\text { Std. } \\
\text { Dev. }\end{array}$ & Mean & $\begin{array}{l}\text { Std. } \\
\text { Dev. }\end{array}$ \\
\hline \multirow{7}{*}{$\begin{array}{l}\text { Periodic } \\
\text { Review }\end{array}$} & $\mathrm{C}$ & Normal & $\mathrm{B}$ & 1528 & 148 & -696 & 6673 & 69039 & 4603 & 3.65 & 0.48 & NA & NA \\
\hline & $\mathrm{C}$ & Uniform & $\mathrm{B}$ & 1467 & 106 & 1668 & 4188 & 66654 & 2863 & 3.96 & 0.20 & NA & NA \\
\hline & $\mathrm{C}$ & $3 \mathrm{PTE}$ & $\mathrm{B}$ & 1403 & 92 & 2856 & 3765 & 64766 & 2697 & 3.98 & 0.16 & NA & NA \\
\hline & $\mathrm{s}$ & Normal & $\mathrm{B}$ & 1732 & 182 & -37238 & 7035 & 42481 & 3554 & 3.97 & 0.27 & NA & NA \\
\hline & $\mathrm{C}$ & Normal & $\mathrm{L}$ & 1598 & 172 & -37266 & 5383 & 68114 & 4565 & 3.20 & 0.43 & 0.8930 & 0.0186 \\
\hline & $\mathrm{C}$ & Uniform & $\mathrm{L}$ & 1581 & 127 & -36604 & 4042 & 63281 & 2764 & 3.03 & 0.17 & 0.8921 & 0.0112 \\
\hline & $\mathrm{C}$ & 3 PTE & $\mathrm{L}$ & 1654 & 126 & -38966 & 4012 & 60082 & 2289 & 3.08 & 0.26 & 0.8950 & 0.0106 \\
\hline ROP,EOQ & C & Normal & $\mathrm{B}$ & 684 & 126 & -20814 & 4543 & 29524 & 0.15 & 0.01 & 0.07 & NA & NA \\
\hline \multirow{4}{*}{$\begin{array}{l}\text { News Boy } \\
\text { Model }\end{array}$} & C & Normal & $\mathrm{L}$ & 112 & 59 & 16724 & 2263 & 0 & 0 & 0.63 & 0.86 & 0.9986 & 0.0025 \\
\hline & $\mathrm{C}$ & Uniform & $\mathrm{L}$ & 60 & 33 & 18638 & 1249 & 0 & 0 & 0.59 & 0.71 & 0.9998 & 0.0002 \\
\hline & $\mathrm{C}$ & 3 PTE & $\mathrm{L}$ & 65 & 32 & 18459 & 1186 & 0 & 0 & 0.57 & 0.71 & 0.9992 & 0.0015 \\
\hline & $S$ & Normal & $\mathrm{L}$ & 5 & 3 & 17961 & 684 & 0 & 0 & 0.72 & 0.79 & 0.9986 & 0.0024 \\
\hline
\end{tabular}

Table 8: Newsboy Approximation: Demand: National distribution Cumulative net cash flow (based on 200 simulation runs)

\begin{tabular}{|c|r|r|r|}
\hline \multirow{2}{*}{} & \multicolumn{3}{|c|}{ Supplier Credit period (3 weeks) } \\
\cline { 2 - 4 } & \multicolumn{3}{|c|}{ Dealer Credit Period } \\
\cline { 2 - 4 } Min & 0 weeks & 6 weeks & End of the season \\
\hline Max & 10602 & -99458 & -382984 \\
\hline Mean & 8541 & -76082 & -335838 \\
\hline Std. Dev. & 818 & -87478 & -359131 \\
\hline
\end{tabular}




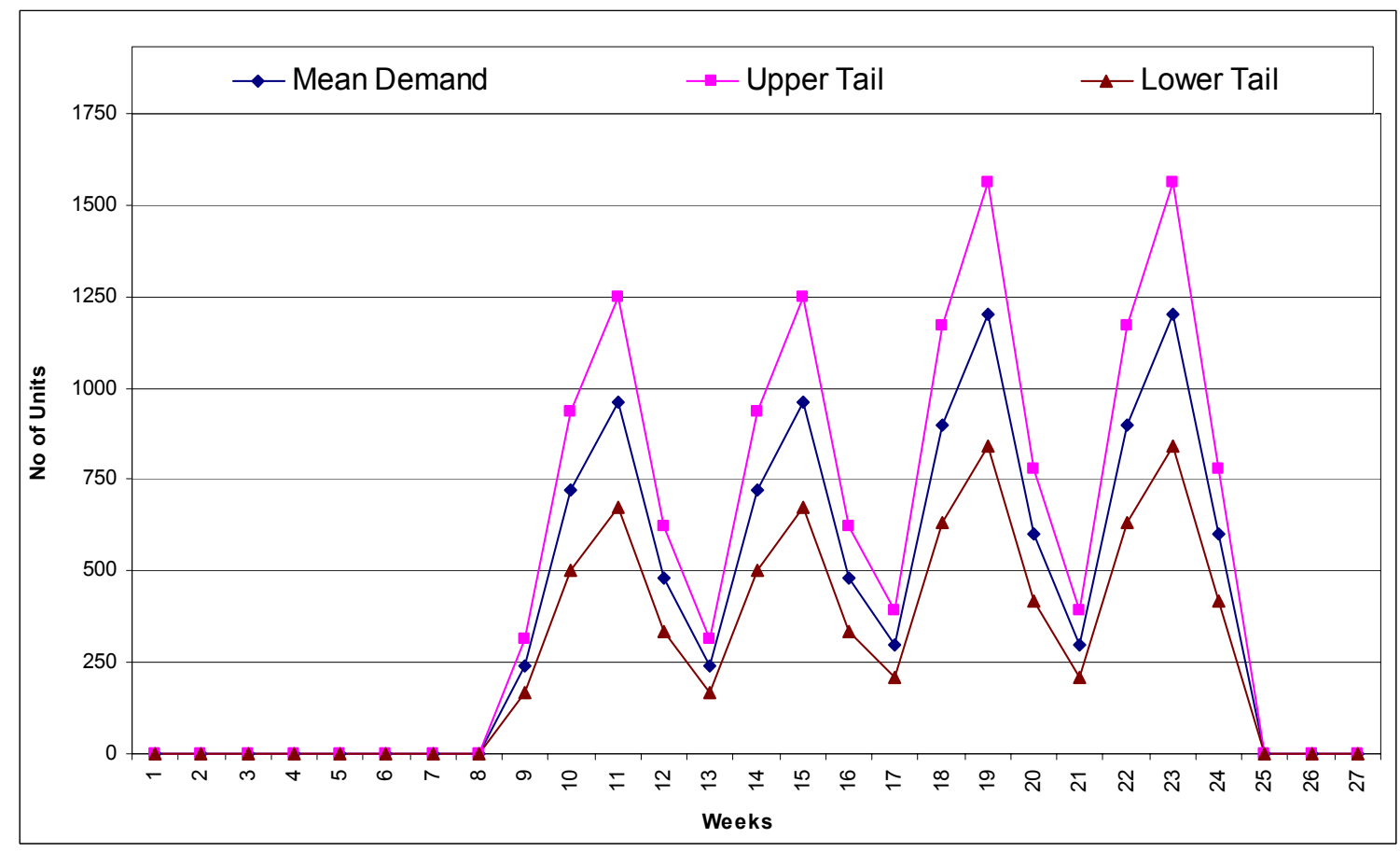

Figure 1: Demand Profile

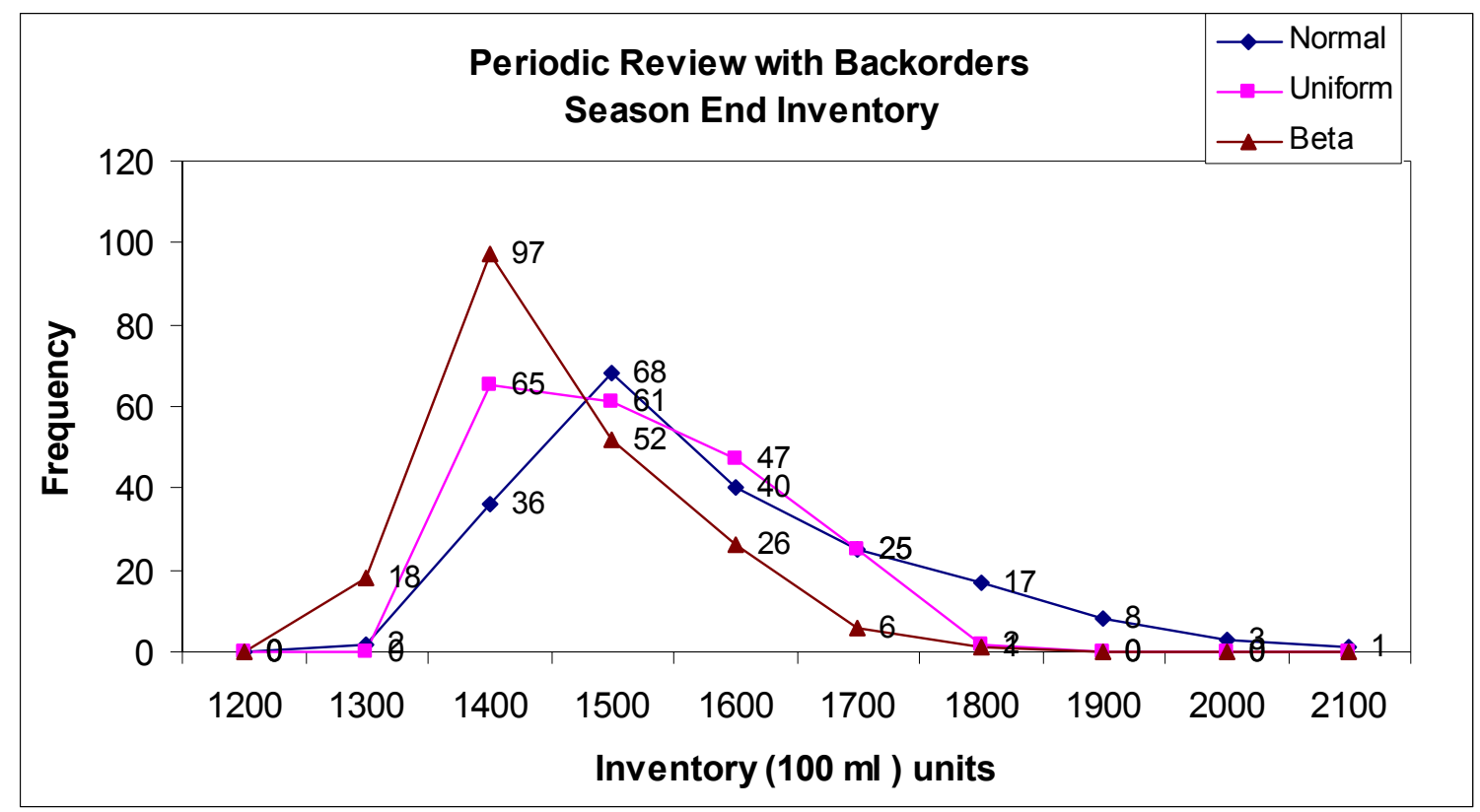

Figure 2: Periodic Review Performance measures 


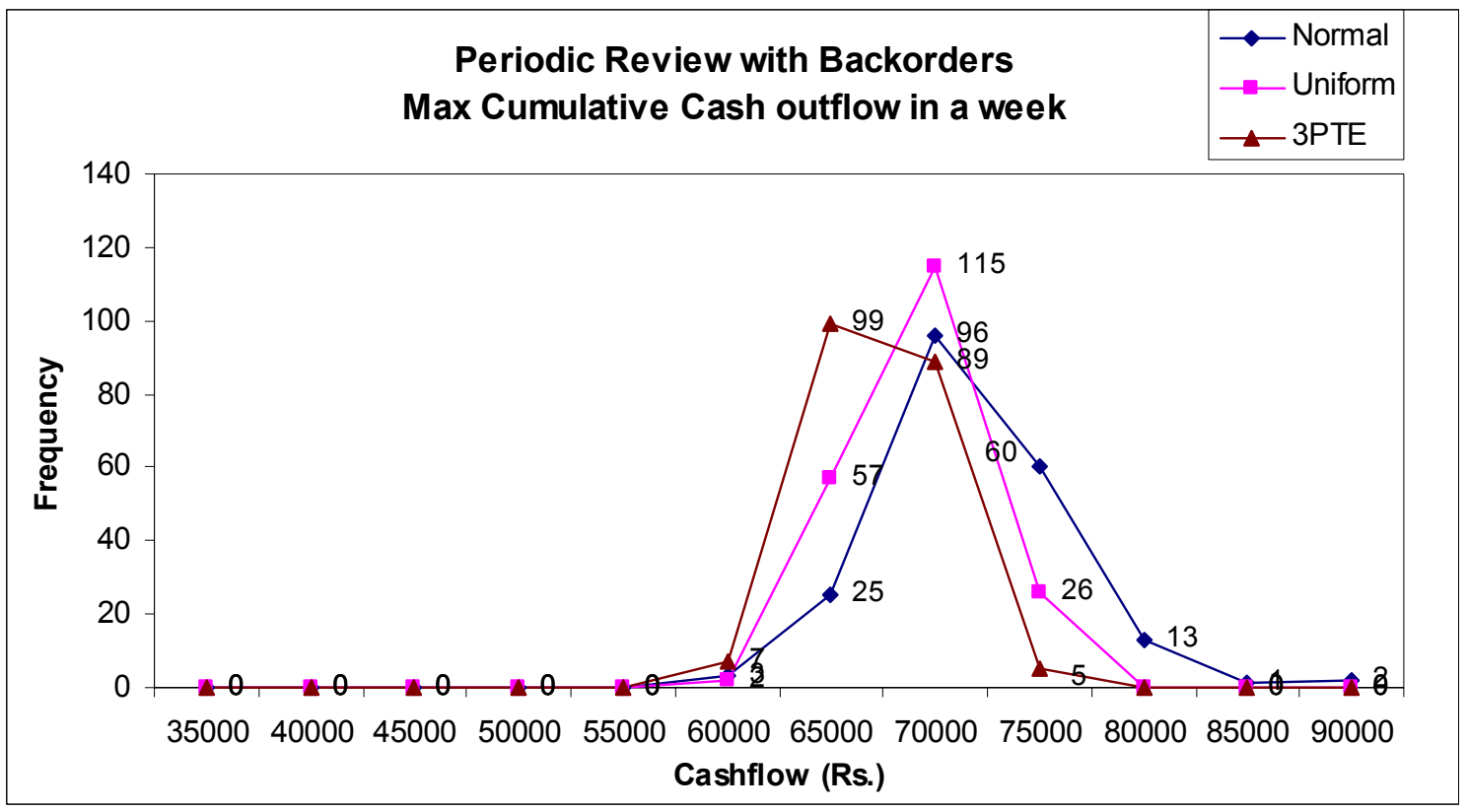

Figure 3: Periodic Review Performance measures

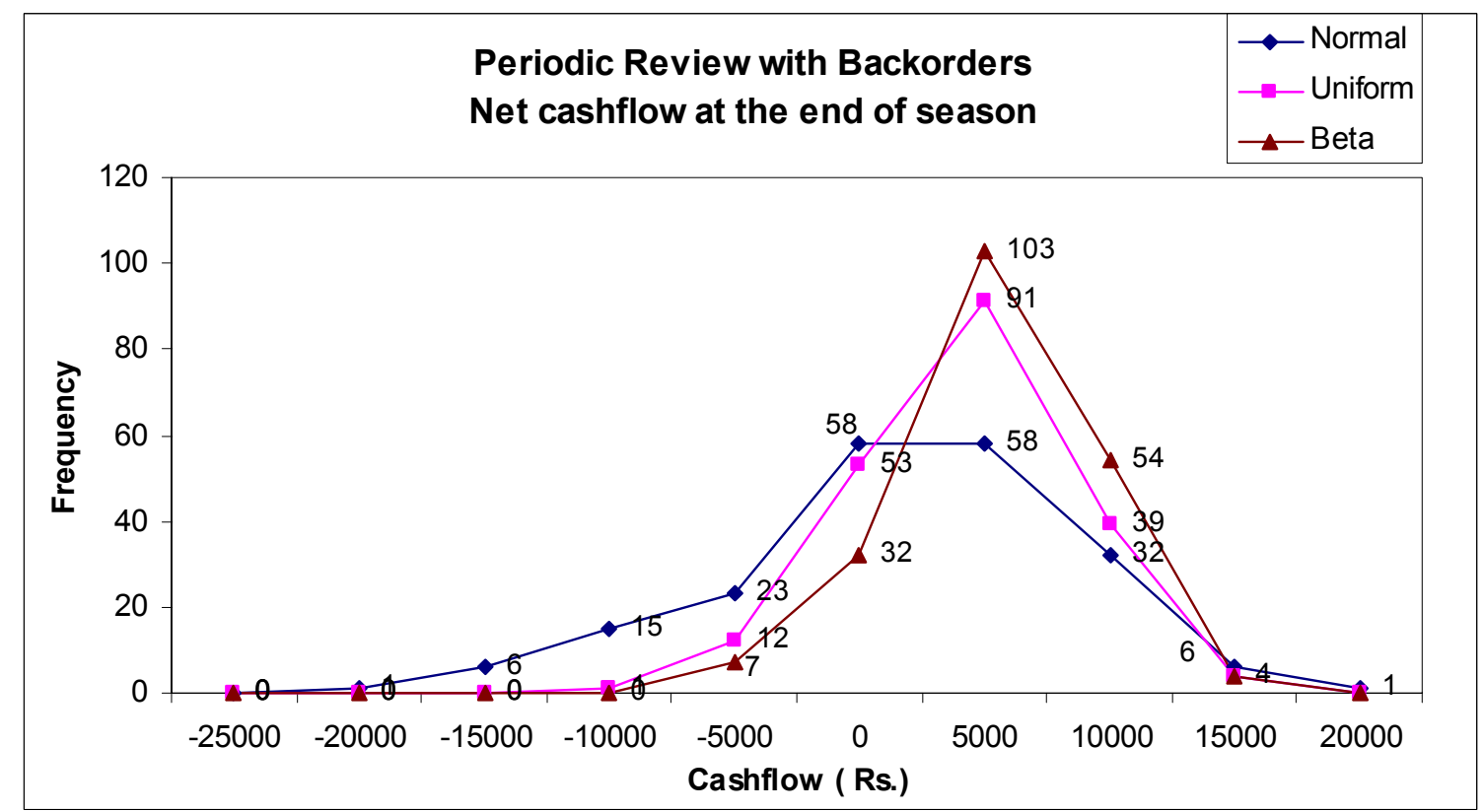

Figure 4: Periodic Review Performance measures 


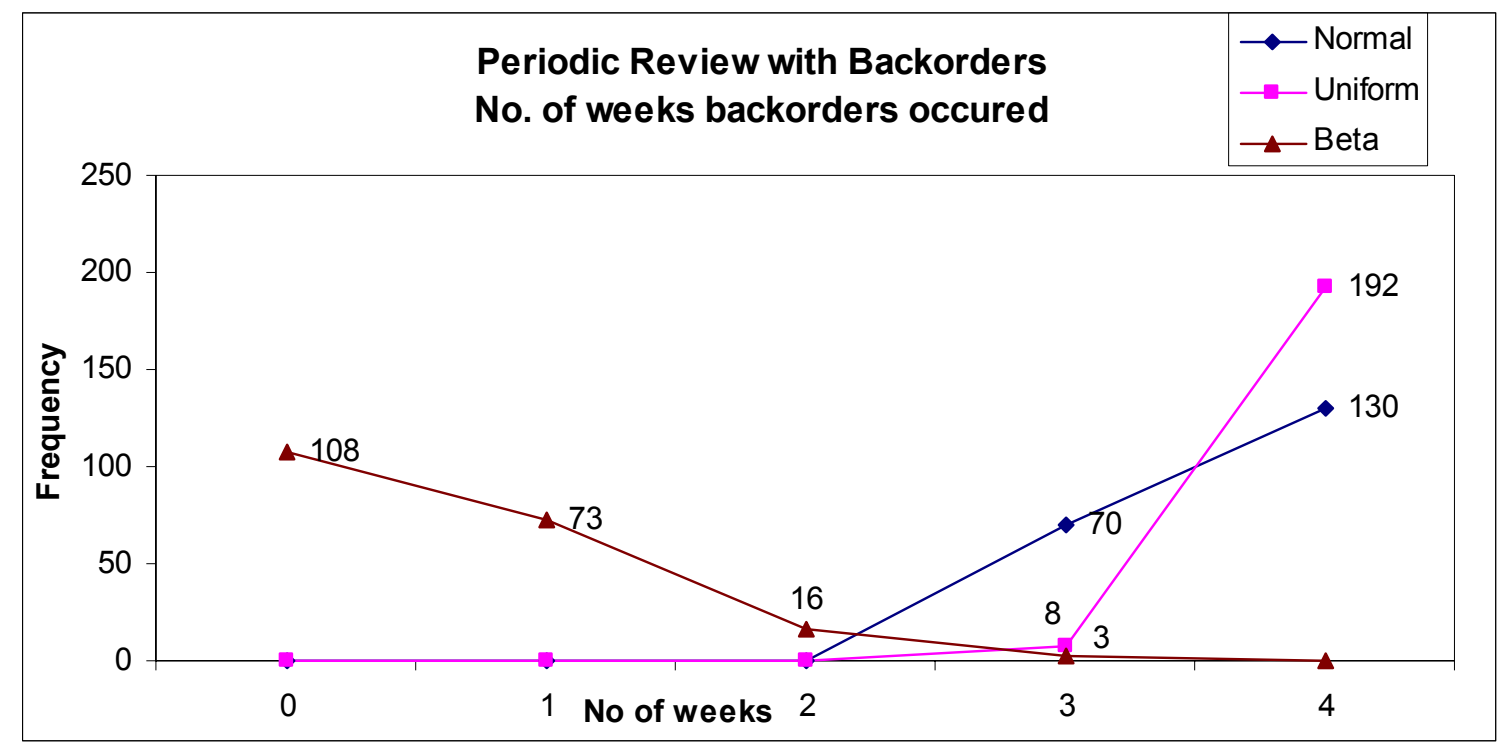

Figure 5: Periodic Review Performance measures

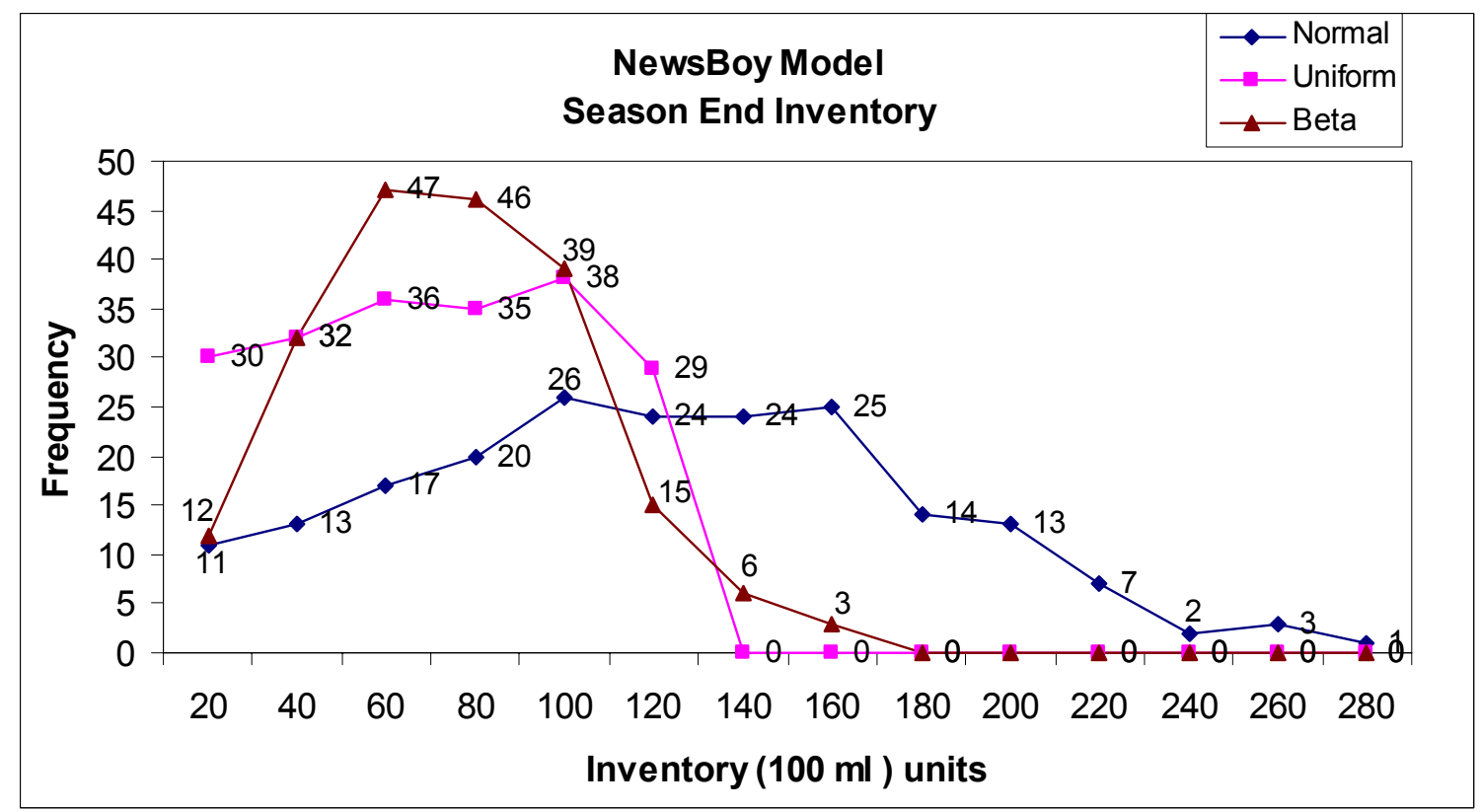

Figure 6: New boy model Performance measures 


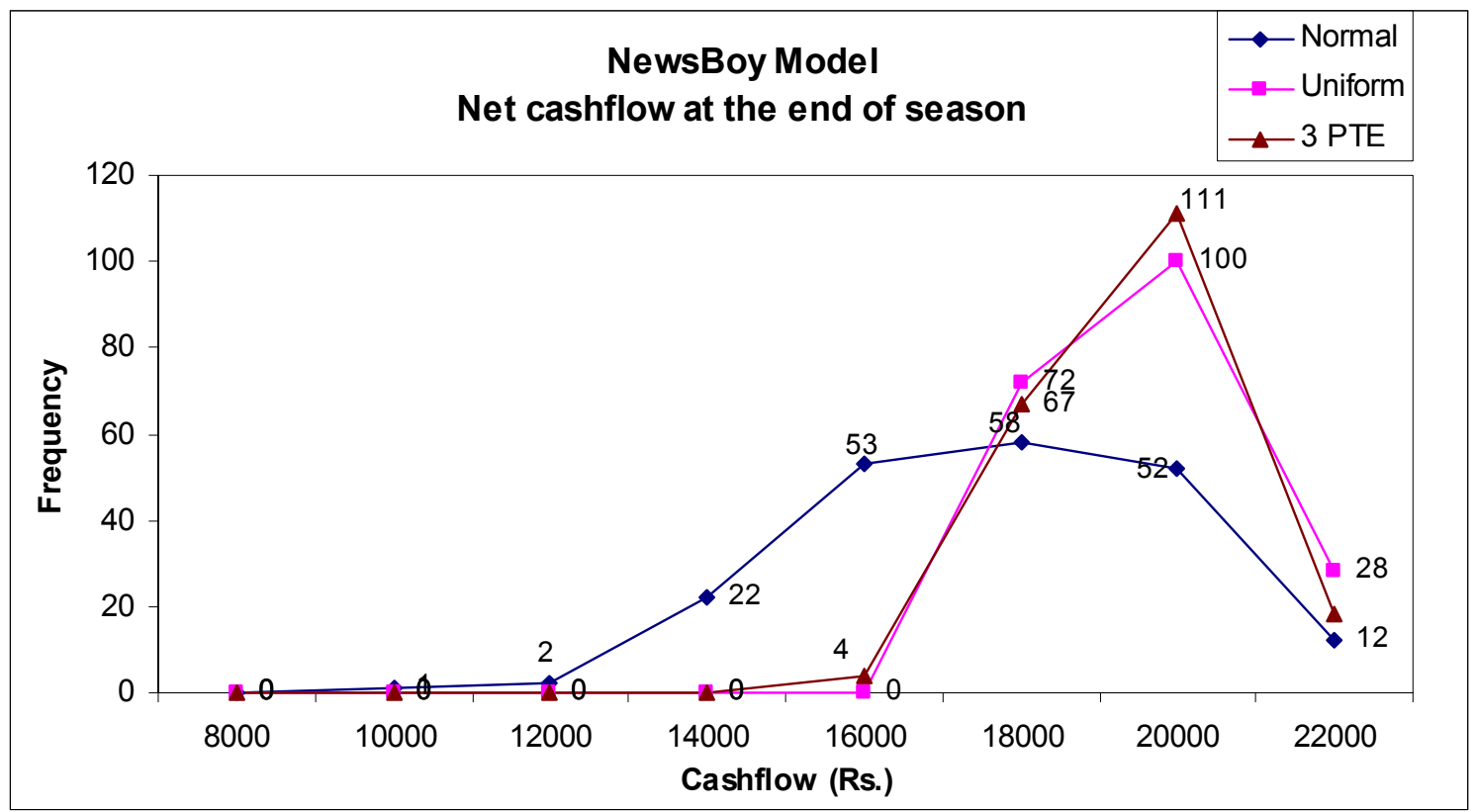

Figure 7: New boy model Performance measures

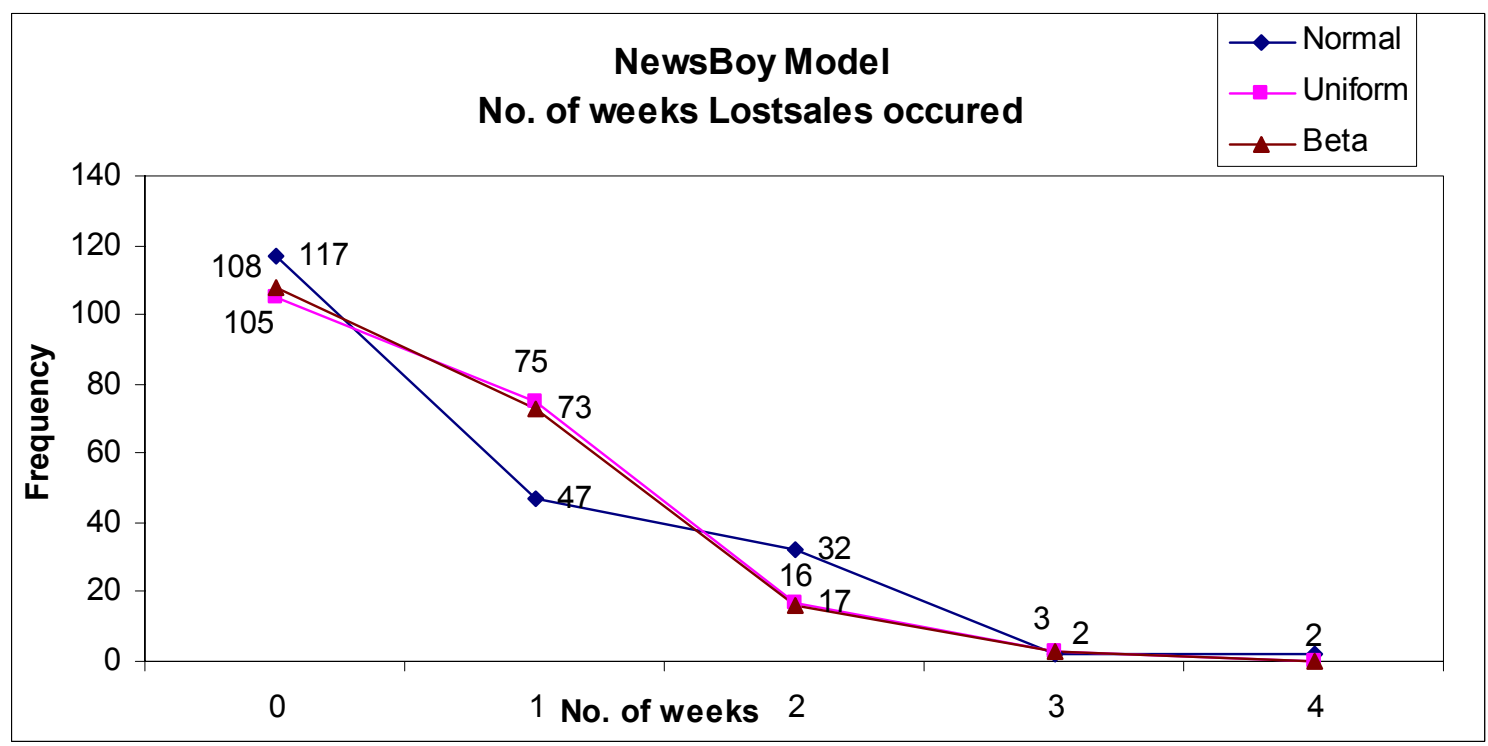

Figure 8: New boy model Performance measures 


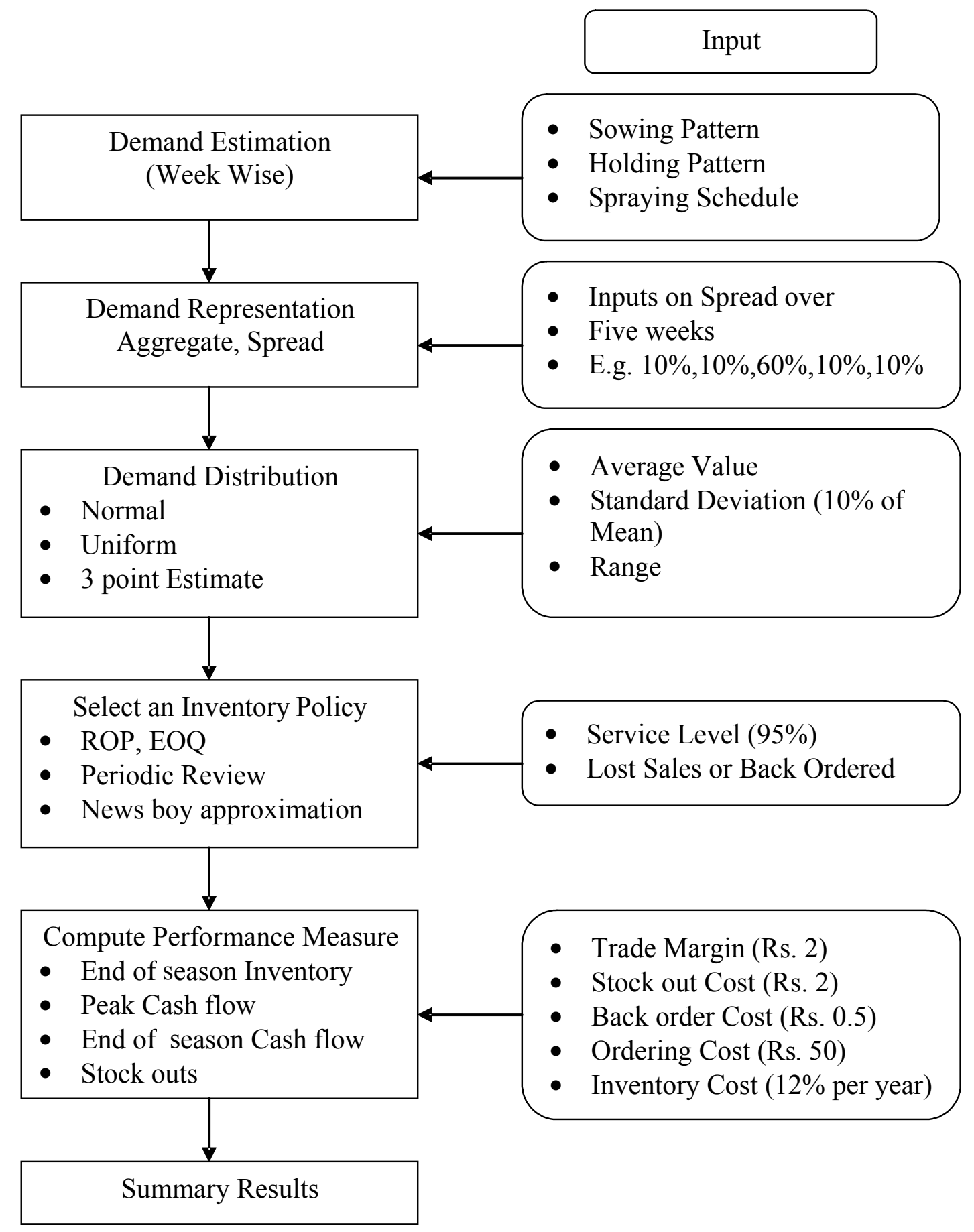

Figure 9: Simulation flow Chart 